\title{
Optimization of potato starch gel formulation as green alternative of animal-sourced gelatin
}

\author{
Faima Atta KHAN ${ }^{1,2 *}$ (D), Muhammad Umair ARSHAD ${ }^{1}$, Syed Shoukat Hussain RIZVI ${ }^{2}$, Kashif AMEER ${ }^{3}$, \\ Faqir Muhammad ANJUM ${ }^{4}$, Muhammad IMRAN ${ }^{1}$ Ali IMRAN ${ }^{1}$
}

\begin{abstract}
This study was aimed at optimization of potato starch gel preparation process by response surface methodology and various process parameters were optimized for textural, gelation and sensory properties. 3D response surface and contour plots showed that independent variables, such as extraction time, extraction temperature and potato starch concentration significantly affected $(p<0.05)$ texture of potato starch gel. It was observed from RSM analysis that target responses regarding texture characteristics (hardness 1 , hardness 2 , springiness and chewiness) were significantly reliant on potato starch conc. followed by extraction time and temperature. $\mathrm{T}_{\mathrm{o}}$ was found in range from 102.98 to $109.87^{\circ} \mathrm{C}$ whereas, the mean $\mathrm{T}_{\mathrm{o}}$ was maintained at $107.20^{\circ} \mathrm{C}$. It was evident from data of experimental runs that $\mathrm{T}_{\mathrm{o}}$ showed relatively consistent tendency in majority of samples while, experimental runs no. 4 and 5 exhibited a maxima and minima of $109.87^{\circ} \mathrm{C}$ and $102.98^{\circ} \mathrm{C}$, respectively. It was evident from $\mathrm{T}_{\mathrm{o}}$ value that starch granules were subjected to degree of disintegration in its internal granules structure, and this disintegration led to polysaccharides release in surrounding medium.
\end{abstract}

Keywords: potato starch; response surface methodology; RVA; PSG; functional food; characterization; gelatinization.

Practical Application: Potato starch gel can be used as natural alternative of gelatin.

\section{Introduction}

Gelatin is a distinctive, multifunctional and innate ingredient which is easily consumable (Brinckmann \& Bachinger, 2005). However, the increasing demand for non-mammalian gelatine for halal and kosher food markets have revived interest in gelatine replacers from plant sources (Jaswir et al., 2016). There are many serious issues regarding unlawful and lawful foods which are affecting Muslims in recent times. It can be produced from tubers like potato starch which is halal, cheapest and excellent (Jamróz et al., 2018).

Gels may be defined as the intermediate form of matter between solid and liquid and show mechanical rigidity (Aguilera, 1992). They consist of polymer molecules crosslinked to form tangled and interconnected molecular network immersed in a liquid medium, which in food system is water (Oakenfull \& Glicksman, 1987). Food technologists use the word 'gel' for high moisture foods that retain their shape when released from their container. However, the most used definition of gel is a rheological one, obtained from dynamic viscometry. According to this definition, a gel is a viscoelastic system with a 'storage modulus' $\left(G^{\prime}\right)$ larger than the 'loss modulus' (G") (De Vries, 2004). Hydrocolloids form gels by physical association of their polymer chains through hydrogen bonding, hydrophobic association and cation mediated cross-linking and differ from synthetic polymer gels, which normally consist of covalently cross-linked polymer chains. Hence, hydrocolloid gels are often referred to as "physical gels" (Phillips \& Williams, 2000).

Ionotropic gelation occurs via cross-linking of hydrocolloid chains with ions, typically a cation mediated gelation process of negatively charged polysaccharides. Examples of such systems are alginate, carrageenan and pectin (Imeson, 2000; May, 2000). Ionotropic gelation is carried out by either diffusion setting or internal gelation. In cold-set gelation. Potato starch is one of the most common polysaccharides naturally occurring, used as thickeners, stabilizer, binging, emulsifying, and gelling agent (Tolstoguzov, 2002). and an important constituent extensively used in the food industry as a functional texturizer. The mucilaginous polysaccharides are used in pharmaceutical industries as a food thickener, gelling agents, and production of edible films (Kennedy, 1979). Starch is stored in granules and found in cereals like maize, wheat, rice, barley and tubers such as potato and tapioca are particularly rich in starch. Starch is generally composed of two different types of polymers like amylose, a linear molecule consisting almost exclusively of $\alpha-1,4$-linked glucose residues and another amylopectin which in addition to linear chains of $\alpha$-1,4-linked glucose also contains $\alpha$-1,6-linked branch points. When heated in water, causes gelatinization

${ }^{1}$ Department of Food Science, Nutrition and Home Economics, Government College University, Faisalabad, Pakistan

${ }^{2}$ Department of Food Science, Cornell University, Ithaca, NY, United States

${ }^{3}$ Department of Food Science and Technology and BK 21 Plus Program, Graduate School of Chonnam National University, Gwangju, South Korea

${ }^{4}$ University of the Gambia, Serrekunda, The Gambia

*Corresponding author: faimakhan264@gmail.com 
produces highly viscous paste. On cooling, gelatinized starch forms a textural gel network if starch concentration has reached a critical concentration. Potato starch is an exclusive among commercial starches in having a high level of phosphate groups that are covalently linked to the $\mathrm{C}_{6}$ and $\mathrm{C}_{3}$ positions of the glucose monomers. These phosphate groups, coupled with the large size of the granules, give this starch a very high swelling power and stable paste properties of this starch (Jobling, 2004). Potato starch exhibits higher swelling power, solubility, paste clarity, and viscosity than wheat, rice, and corn starches. Potato starch shows a higher tendency toward retrogradation compared with cereal starches (Singh et al., 2003). For the development of the initial gel network amylose is a key player having a tendency to quickly form connected double-helix aggregates. Amylopectin gelation, on the other hand is a slower process involving weaker reversible chain associations (Kaper et al., 2004). In this study, the manufacturing of potato starch gel was optimized by response surface methodology and various operational parameters were optimized for textural, gelation and sensory properties.

\section{Materials and methods}

\subsection{Sample procurement}

Commercial (unmodified) potato starch was obtained from National Starch \& Chemical Co. (NJ, USA), KGM (95\% purity), TIC organic ${ }^{\circledR}$ Konjac HV (White Marsh, MD, USA) was supplied by Cornell University Food Science Department, Ithaca, USA. Sodium azide (99\% extra pure) was purchased. Thermo Fisher Scientific Acro's Organics (Morris, NJ, USA), Lecithin powder was supplied from (Alfa Chem 2 Harbor Way Kings Point, NY, USA) respectively.

\subsection{Moisture content}

Moisture content of potato starch powders was measured in a hot-air cabinet dryer at Department of Food Science, Cornell University USA. An aliquot of $5 \mathrm{~g}$ was weighed precisely and heated for $3 \mathrm{~h}$ at $105^{\circ} \mathrm{C}$. Samples were left to cool in a desiccator until room temperature was reached and then weighed. Measurements were performed in triplicate. Moisture content was calculated as follows (Equation 1):

$$
M C=\frac{m_{i}-m_{f}}{m_{i}} \times 100
$$

where $\mathrm{m}_{\mathrm{i}}$ is the initial mass and $\mathrm{m}_{\mathrm{f}}$ is the final mass after drying (Freschi et al., 2014).

\subsection{Preparation of potato starch gel}

Potato Starch gels were prepared with some modification following (Liu \& Xu, 2019). Initially, Potato Starch powder was weighed in different beakers with various concentrations (10, 15, 20, 25 and $30 \%, w / w$ ) and $0.02 \%$ of sodium azide (Gojira Fine Chemicals, Ohio, USA) (to inhibit microorganisms), $(0.25,0.75$ and $1 \% \mathrm{w} / \mathrm{w}$ ) KGM powder (to control the syneresis in gel) and $(0.5 \%)$ lecithin power was primarily dissolved thoroughly in deionized water with continuous magnetic stirring for $30 \mathrm{~min}$ at room temperature to avoid the formation of starch lump, covered with parafilm to avoid evaporation. Manually shaken until gelation occurred, potato starch mixtures were heated in boiled water for $20,30,35,60$ and 72 mins in the bath at temperatures $\left(55,65,75,85\right.$, and $\left.95^{\circ} \mathrm{C}\right)$, then with continuous manual stirring for the first $10 \mathrm{~min}$. The paste was poured into a beaker $(20 \mathrm{~mm}$ in height and $40 \mathrm{~mm}$ in diameter) and covered with parafilm to prevent evaporation loss. All samples were then cooled and stored at $4{ }^{\circ} \mathrm{C}$ in refrigerator overnight for maturation of gels.

\subsection{Determination of potato starch gel pasting characteristics}

The pasting properties of the potato starch with KGM were determined using a Rapid Visco-Analyzer Perten (model RVA 4, Newport Scientific, Australia). First KGM was dispersed in $25 \mathrm{~mL}$ distilled water with magnetic stirring. For each run, an appropriate amount of potato starch $(2.5,3.0$, and $3.5 \mathrm{~g})$ were added slowly to KMG solutions to avoid any lump formation. The slurries were rapidly mixed at $50^{\circ} \mathrm{C}$ for $1 \mathrm{~min}(960 \mathrm{rpm})$ then pasted while being stirred at $160 \mathrm{rpm}$. The at a rate of $13^{\circ} \mathrm{C} / \mathrm{min}$, held at $95^{\circ} \mathrm{C}$ for $3 \mathrm{~min}$, cooled to $50^{\circ} \mathrm{C}$ at $13^{\circ} \mathrm{C} / \mathrm{min}$ and held at $50^{\circ} \mathrm{C}$ for $4 \mathrm{~min}$. After detection, peak viscosity (PV), trough viscosity (TV), breakdown viscosity (BV), final viscosity (FV), setback viscosity (SV) as well as pasting temperature (PT) were obtained. All the measurements were done in triplicate (Zhang et al., 2019; Shafie et al., 2016).

\subsection{Determination of gel pasting characteristics}

A Perten rapid visco analyzer (RVA, Newport Scientific, Australia) was used to record and analyse the pasting properties of the rice flours. Rice flour suspension was prepared by adding $3.00 \pm 0.01 \mathrm{~g}$ of the flour directly into a metal RVA canister containing $25 \mathrm{~mL}$ of distilled water. Paddle was jog up and down to remove any lump that formed. The pasting profile was recorded in triplicate under a constant shear rate $(160 \mathrm{rpm})$ with heating and cooling cycles of $50{ }^{\circ} \mathrm{C}$ to $95^{\circ} \mathrm{C}$ for $13 \mathrm{~min}$ (Association of Official Analytical Chemists, 2000). Peak viscosity (PV), trough/hold viscosity (HV), breakdown (BD), final viscosity $(\mathrm{FV})$, setback $(\mathrm{SB})$, pasting temperature $(\mathrm{PT})$ and peak time were recorded from the RVA curve. Stability ratio was the ratio of hold viscosity to peak viscosity and setback ratio was the ratio of final viscosity to hold viscosity.

\subsection{Determination of gel texture characteristics}

Texture of potato starch gel was determined in a texture analyzer TA-XT plus, Stable Micro Systems, (Texture Technologies crop., Scarsdale, NY, USA) and property of Cornell university USA. For Experiments were performed $24 \mathrm{~h}$ after sample preparation to allow full gel maturation. Before textural testing, samples were equilibrated for about $1 \mathrm{~h}$ at $25^{\circ} \mathrm{C}$. Each sample container was placed upright on the metal plate, Equipped with a $50 \mathrm{~kg}$ cell load, cylindrical probe (P/5), a control force of $5 \mathrm{~g}$ was used to compress the gels to $40 \%$ of the original height. The test speed of $0.5 \mathrm{~mm} / \mathrm{s}$, with a $5 \mathrm{~g}$ tiger force to compress the gel twice. From TPA curve Note here that hardness 1 and 2 (peak force of the first cycle), springiness (related to elasticity), and chewiness were determined. The analysis was tested in triplicate (Liu \& Xu, 2019). 


\subsection{Determination of gel texture characteristics}

Texture profile analysis (TPA) measurements were conducted on a texture analyser (TA-XT plus, Stable Micro Systems, UK) with a load cell of $5 \mathrm{~kg}$ as reported elsewhere. For this purpose, starch gel samples prepared in cylindrical flasks filled up to $80 \%$ ( $4.5 \mathrm{~cm}$ height and $2.5 \mathrm{~cm}$ diameter) were submitted to a double penetration (compressed) using a cylindrical probe $\mathrm{P} / 05 \mathrm{R}$ ( $0.6 \mathrm{~mm}$ radius, $2 \mathrm{~mm} / \mathrm{s}$ crosshead speed, and $5 \mathrm{~mm}$ penetration). Experiments were performed $24 \mathrm{~h}$ after sample preparation to allow full gel maturation. Before textural testing, samples were equilibrated for about $1 \mathrm{~h}$ at $25^{\circ} \mathrm{C}$. Note here that hardness 1 and 2 (peak force of the first cycle), springiness (related to elasticity), and chewiness were determined (Torres et al., 2018).

\section{Determination of gelation characteristics}

The gelation parameters were determined by digital scanning colorkmeter with a Shimadzu calorimeter, model DSC-50 (Shimadzu Corp. Tokyo, Japan), These parameters were based on the conventional laboratory program and an appropriate method. Transition temperatures were recorded from a plot of heat flow vs. temperature $\left(30-500{ }^{\circ} \mathrm{C}\right)$. The peak temperature $\left(\mathrm{T}_{\mathrm{p}}\right)$ of gelatinization was determined from the DSC curve with Shimadzu TASYS software. The reaction heat was determined by using the area of the peaks between the onset temperature $\left(\mathrm{T}_{0}\right)$ and the end-temperature from the DSC curve. Samples (2.00 mg) were weighed to the nearest $\pm 0.01 \mathrm{mg}$ and sealed in aluminium pans. The images were captured by means of DSC coupled to the photo visual system under similar conditions of conventional DSC. Medium and standard deviation values were determined from triplicates of DSC curves. The instrument was calibrated via the melting points of indium $\left(156.6 \pm 0.3{ }^{\circ} \mathrm{C}\right)$ and zinc $\left(419.6 \pm 0.3{ }^{\circ} \mathrm{C}\right)$ standards. The heat flow and enthalpy were calibrated via the heat of fusion of indium $(28.59 \pm 0.30 \mathrm{~J} / \mathrm{g})$ under the same conditions as for the samples.

\subsection{Measurement of thermal properties potato starch gel (DSC)}

The experiment was carried out in Food Engineering lab. In Stocking hall Cornell university USA, Differential Scanning Calorimeter (DSC, Mettler-Toledo Inc., Columbus, OH, U.S.A) (Reddy et al., 2015). A starch sample was precisely weighed (2 mg, dry weight: DW basis) and mixed with $7 \mu \mathrm{L}$ distilled water to make starch suspension in an aluminium pan, and distilled water was added to the pan until the starch concentration reached $40 \%$ (w/w, DW basis). The sample pan was sealed. The weighed sample was scanned at a rate of $5^{\circ} \mathrm{C} /$ min over a temperature range of $25-110^{\circ} \mathrm{C}$, and an empty pan was taken as a control. Three gelatinization temperatures, including onset temperature $\left(\mathrm{T}_{\mathrm{o}}\right)$, peak temperature $\left(\mathrm{T}_{\mathrm{p}}\right)$ and ending temperature $\left(\mathrm{T}_{\mathrm{e}}\right)$, were obtained from the thermal profiles. The analysis was performed in triplicate.

\subsection{Experimental design}

All experiments were carried in accordance with central composite design configuration. The ranges of CCD parameters are given in Table 1 .

\subsection{Statistical analysis}

The experimental design and data analysis were performed using the Design-Expert software (ver. 8.0.6, Stat-Ease Inc., Minneapolis, USA). All experiments were conducted in in triplicates and presented as mean \pm standard deviation (S.D.). Statistical significance of the data obtained was analyzed by one-way analysis of variance (ANOVA) whereas differences between the means were compared by Duncan's multiple-range test using SPSS version 18.0 at significance level of $p<0.05$.

\section{Results and discussion}

\subsection{RSM modelling for statistical optimization}

This RSM-based process optimization offers several advantages, such as reduced operating cost of hands-on experiments by decreasing number of experimental runs, decrease in numerical noise with improved assessment of process variables in interactive manner and optimization of responses within region of interest in designed experiments. Results of target responses regarding pasting, texture and gelation parameters from experimental runs performed under CCD configuration, were shown in Tables 1-3 obtained as function of independent process variables ( $\mathrm{X}_{1}$ : extraction time $(\mathrm{min}), \mathrm{X}_{2}$ : extraction temperature $\left({ }^{\circ} \mathrm{C}\right)$ and $\mathrm{X}_{3}$ : Potato Starch Conc. (\%). The second order quadratic model equations of target responses were obtained in coded form after achieving fitting by multiple linear regression (MLR) analysis to obtain good fit and were shown in following subsections.

Analysis of variance (ANOVA) was employed to evaluate second order quadratic model equations with respect to their statistical significance (Table 2 ). Probability values ( $p$-values) were employed as valid indicator to evaluate model significance, whereas, further evidence was achieved by analyzing goodness of fit ( $\mathrm{R}^{2}$ values) between model-predicted and experimental values of target responses. Each target response exhibited coefficient values which were utilized in formulation of final predictive equations, while insignificant terms were neglected. High model significance was indicative from the obtained lower probability values $(p<0.0001)$. The relatively higher $\mathrm{R}^{2}$ values validated the statistical significance of formulated regression models. Model validity was also endorsed by the non-significant lack of fit value $(>0.05)$ and hence suggested better precision accompanied by higher degree of reliability. The fitted model for all target responses revealed significant effect of independent

Table 1. Independent variables and their levels.

\begin{tabular}{lccccccc}
\hline \multicolumn{1}{c}{ Independent Variables } & Symbol & Unit & -2 & -1 & 0 & 1 \\
\hline Extraction time & $\mathrm{X}_{1}$ & Min & 20 & 30 & 40 & 60 & 72 \\
Extraction temperature & $\mathrm{X}_{2}$ & ${ }^{\circ} \mathrm{C}$ & 55 & 65 & 75 & 85 & 95 \\
Potato Starch Conc. & $\mathrm{X} 3$ & $\%$ & 10 & 15 & 20 & 25 & 30 \\
\hline
\end{tabular}


Khan et al.

Table 2. Central composite design configuration of target responses of pasting parameters.

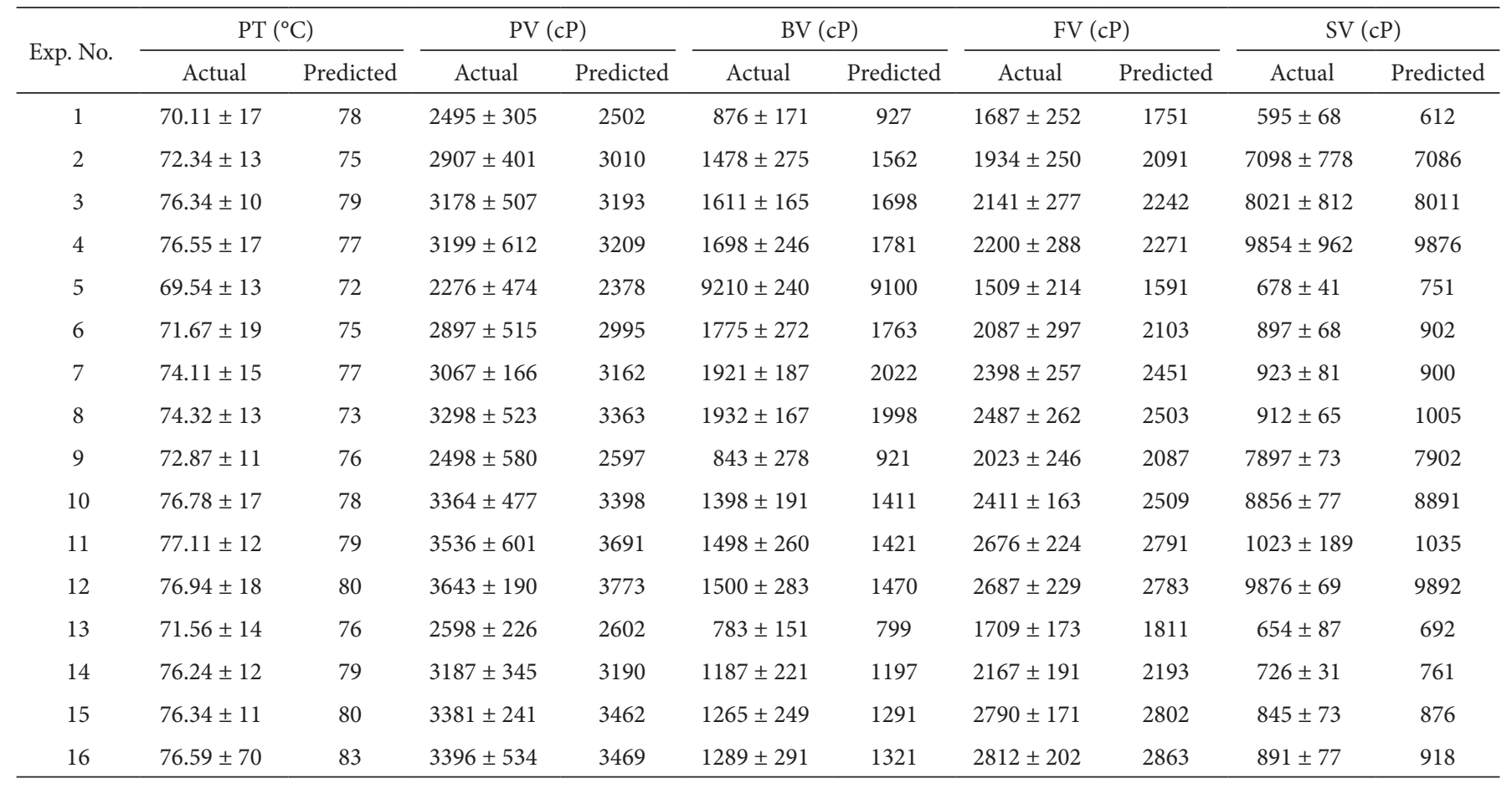

Table 3. Central composite design configuration of target responses of texture parameters.

\begin{tabular}{|c|c|c|c|c|c|c|c|c|}
\hline \multirow{2}{*}{ Exp. No. } & \multicolumn{2}{|c|}{ Hardness $1(\mathrm{~g})$} & \multicolumn{2}{|c|}{ Hardness 2 (g) } & \multicolumn{2}{|c|}{ Springiness $(\mathrm{mm})$} & \multicolumn{2}{|c|}{ Chewiness (mJ) } \\
\hline & Actual & Predicted & Actual & Predicted & Actual & Predicted & Actual & Predicted \\
\hline 1 & $39.24 \pm 12$ & 42 & $42.36 \pm 15$ & 44 & $13.78 \pm 9$ & 15 & $1.11 \pm 1$ & 1.14 \\
\hline 3 & $33.11 \pm 12$ & 35 & $33.76 \pm 11$ & 35 & $14.59 \pm 5$ & 16 & $1.45 \pm 4$ & 1.52 \\
\hline 4 & $31.23 \pm 9$ & 33 & $27.98 \pm 15$ & 29 & $14.94 \pm 7$ & 17 & $1.73 \pm 3$ & 1.71 \\
\hline 6 & $35.38 \pm 17$ & 39 & $37.91 \pm 12$ & 40 & $14.98 \pm 6$ & 17 & $1.64 \pm 2$ & 1.69 \\
\hline 7 & $32.11 \pm 12$ & 33 & $31.97 \pm 13$ & 33 & $15.21 \pm 7$ & 19 & $1.83 \pm 1$ & 1.89 \\
\hline 8 & $29.58 \pm 14$ & 31 & $26.87 \pm 14$ & 27 & $15.34 \pm 4$ & 18 & $2.05 \pm 1$ & 2.11 \\
\hline 9 & $40.26 \pm 11$ & 41 & $35.45 \pm 17$ & 38 & $13.98 \pm 3$ & 16 & $1.56 \pm 2$ & 1.59 \\
\hline 13 & $41.22 \pm 11$ & 43 & $39.96 \pm 16$ & 42 & $14.23 \pm 9$ & 16 & $1.24 \pm 1$ & 1.31 \\
\hline 14 & $36.87 \pm 12$ & 37 & $37.22 \pm 11$ & 39 & $14.97 \pm 4$ & 16 & $1.56 \pm 2$ & 1.61 \\
\hline 15 & $32.23 \pm 13$ & 33 & $31.47 \pm 10$ & 34 & $14.93 \pm 5$ & 18 & $1.77 \pm 2$ & 1.81 \\
\hline 16 & $30.78 \pm 15$ & 31 & $28.86 \pm 12$ & 30 & $15.06 \pm 8$ & 19 & $2.04 \pm 1$ & 2.16 \\
\hline
\end{tabular}

process variables $\left(\mathrm{X}_{1}-\mathrm{X}_{3}\right)$ on individual target responses related to pasting $\left(\mathrm{Y}_{1}\right.$ to $\left.\mathrm{Y}_{5}\right)$, texture $\left(\mathrm{Y}_{6}\right.$ to $\left.\mathrm{Y}_{9}\right)$ and gelation $\left(\mathrm{Y}_{10}\right.$ to $\left.Y_{12}\right)$ properties. Higher degree of significance $(p<0.0001)$ was found from regression analysis equatorial model terms, such as main, cross-product (squared) and interaction effects. On basis of MLR equations, three-dimensional (3D) surface and contour plots were formed for elucidating interaction effects exhibited by independent process variables responsible for gel formulation. 3D plots are more useful usually in terms of their rising ridge or saddle forms to get profound understanding of main and cross-product effects on individual target responses (Ameer et al., 2017). In addition, the actual experimental values showed fair match with those of RSM model-predicted values (Tables 2-4). 
Table 4. Central composite design configuration of target responses of gelation characteristics.

\begin{tabular}{|c|c|c|c|c|c|c|}
\hline Exp. No. & \multicolumn{2}{|c|}{ To $\left({ }^{\circ} \mathrm{C}\right)$} & \multicolumn{2}{|c|}{$\operatorname{Tp}\left({ }^{\circ} \mathrm{C}\right)$} & \multicolumn{2}{|c|}{$\mathrm{Te}\left({ }^{\circ} \mathrm{C}\right)$} \\
\hline 1 & $104.11 \pm 14$ & 108 & $110.23 \pm 11$ & 118 & $100.78 \pm 8$ & 105 \\
\hline 2 & $107.65 \pm 10$ & 109 & $114.87 \pm 10$ & 116 & $107.94 \pm 15$ & 109 \\
\hline 3 & $109.26 \pm 10$ & 112 & $117.89 \pm 17$ & 122 & $119.87 \pm 12$ & 123 \\
\hline 6 & $105.56 \pm 16$ & 108 & $113.56 \pm 12$ & 117 & $11.43 \pm 12$ & 17 \\
\hline 7 & $108.89 \pm 10$ & 110 & $116.98 \pm 14$ & 119 & $115.84 \pm 17$ & 119 \\
\hline 8 & $109.11 \pm 15$ & 111 & $119.42 \pm 12$ & 112 & $122.86 \pm 10$ & 129 \\
\hline 9 & $103.56 \pm 13$ & 105 & $108.34 \pm 10$ & 110 & $104.21 \pm 9$ & 109 \\
\hline 12 & $108.98 \pm 17$ & 110 & $117.95 \pm 18$ & 120 & $124.11 \pm 13$ & 129 \\
\hline 13 & $105.34 \pm 13$ & 107 & $111.21 \pm 13$ & 115 & $107.24 \pm 17$ & 109 \\
\hline 14 & $107.97 \pm 16$ & 109 & $114.87 \pm 12$ & 117 & $114.98 \pm 11$ & 116 \\
\hline 15 & $109.21 \pm 12$ & 114 & $117.25 \pm 18$ & 121 & $119.54 \pm 13$ & 125 \\
\hline 16 & $109.45 \pm 15$ & 116 & $119.78 \pm 16$ & 123 & $122.87 \pm 18$ & 129 \\
\hline
\end{tabular}

\subsection{Effects of independent variables on gel pasting properties}

The results of pasting properties of potato starch gels obtained under CCD configuration are shown in Table 2. The pasting temperature (PT) of gels obtained from all experimental runs ranged from 69.54 to $77.11^{\circ} \mathrm{C}$. The average recorded PT from all runs of CCD configuration was found to be $74.35^{\circ} \mathrm{C}$. It was evident from the results that central point value of PT has shown most significant influence on gel formation from potato starch. The experimentally verified values of PT from run No. 5 and 11 were shown to be in fair agreement with those of mode-predicted values. The potato starch granules exhibit size in the range of 15-70 $\mu \mathrm{m}$ and consists of considerably large amount of amylopectin (about 79\%) as compared to amylose content (21\%). The starches with rich amylopectin content have been reported to exhibit substantially higher PV. Response surface and contour plots for pasting parameters; PT, PV, BV, FV and SV are given in Figure 1.

The peak viscosity $(\mathrm{PV})$ of gels obtained from all experimental runs ranged from $2276 \mathrm{cP}$ to $3643 \mathrm{cP}$. The average recorded PV from all runs of CCD configuration was found to be $3058 \mathrm{cP}$. It was evident from the results that $\mathrm{PV}$ exerted significant influence on gel formulation from potato starch. The experimentally verified values of PT from run No. 5 and 11 were shown to be in fair agreement with those of mode-predicted values. The highest PV (3643 cP) was observed in gel obtained from run No. 12 at following process variables; $\mathrm{X}_{1}$ : extraction time $(46 \mathrm{~min})$, $\mathrm{X}_{2}$ : extraction temperature $\left(75^{\circ} \mathrm{C}\right)$ and $\mathrm{X}_{3}$ : potato starch conc. (37\%). Whereas, the lowest PV $(2276 \mathrm{cP})$ was observed in gel obtained from run No. 5 at following process variables; $\mathrm{X}_{1}$ : extraction time $(72 \mathrm{~min}), \mathrm{X}_{2}$ : extraction temperature $\left(95^{\circ} \mathrm{C}\right)$ and $\mathrm{X}_{3}$ : potato starch conc. $(30 \%)$.

The breakdown viscosity (BV) of gels obtained from all experimental runs ranged from $783 \mathrm{cP}$ to $9210 \mathrm{cP}$. The average recorded $\mathrm{BV}$ from all runs of $\mathrm{CCD}$ configuration was found to be $1891 \mathrm{cP}$. It was evident from the results that BV exerted significant influence on gel formulation from potato starch. The experimentally verified values of BT from run No. 5 and 13 were shown to be in fair agreement with those of mode-predicted values. BV showed significant variations with corresponding rises in extraction time and temperature. BV represents possible susceptibility of starch granules breakdown after exposure to elevated heating temperatures and shearing (Kaur et al., 2007). The susceptibility of starch granules to shear disintegration shows increasing tendency in starches with low amylose content after swelling (Kaur et al., 2007). Similarly, final viscosity (FV) of gels obtained from all experimental runs ranged from $1509 \mathrm{cP}$ to $2812 \mathrm{cP}$. The average recorded FV from all runs of CCD configuration was found to be $2232 \mathrm{cP}$. It was evident from the results that FV exerted significant $(p<0.05)$ influence on gel formulation from potato starch. The experimentally verified values of FV from run No. 5 and 16 were shown to be in fair agreement with those of mode-predicted values. FV showed significant variations with corresponding rises in extraction time and temperature. The gels showed setback viscosity (SV) from all experimental runs in the range of $595 \mathrm{cP}$ to $9876 \mathrm{cP}$. The average recorded SV from all runs of CCD configuration was found to be $3734 \mathrm{cP}$. It was evident from the results that SV exerted significant $(p<0.05)$ influence on gel formulation from potato starch. The experimentally verified values of FV from run 

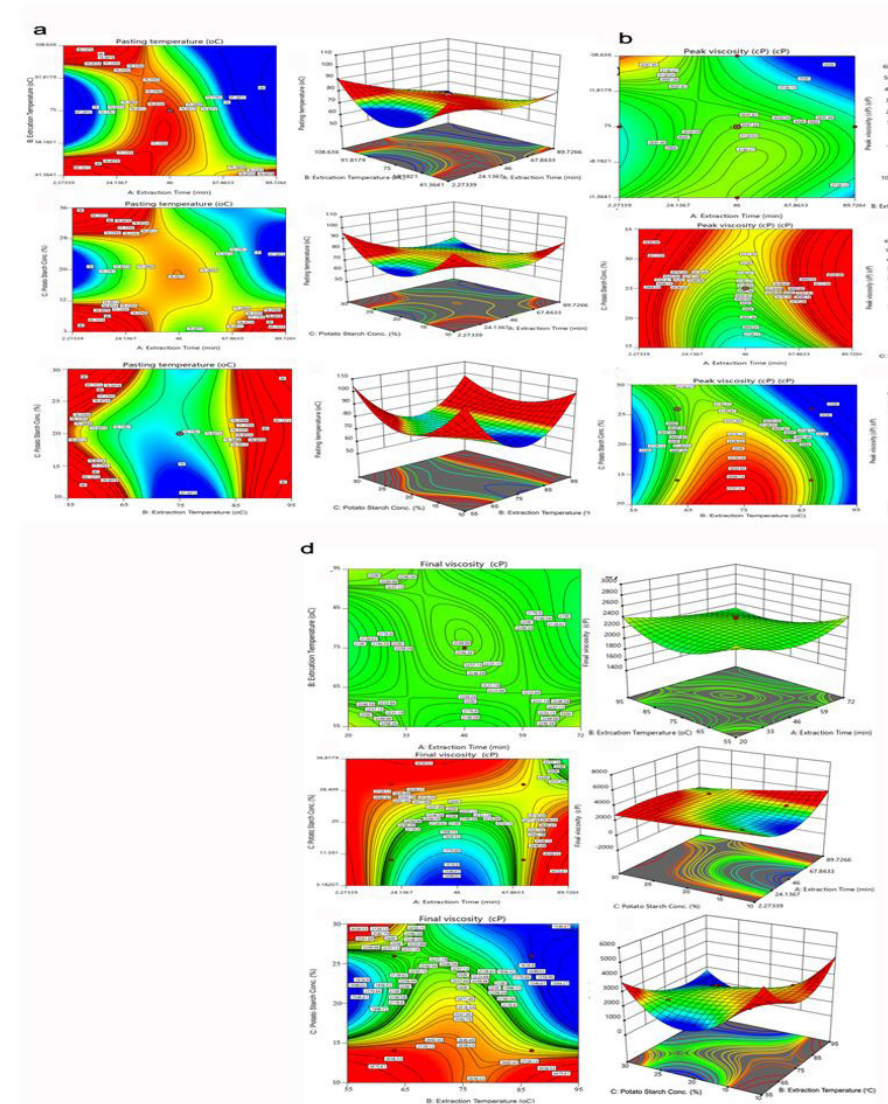

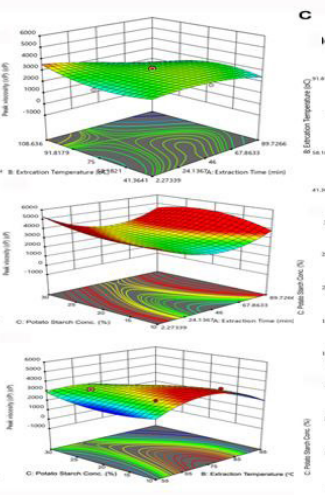

e
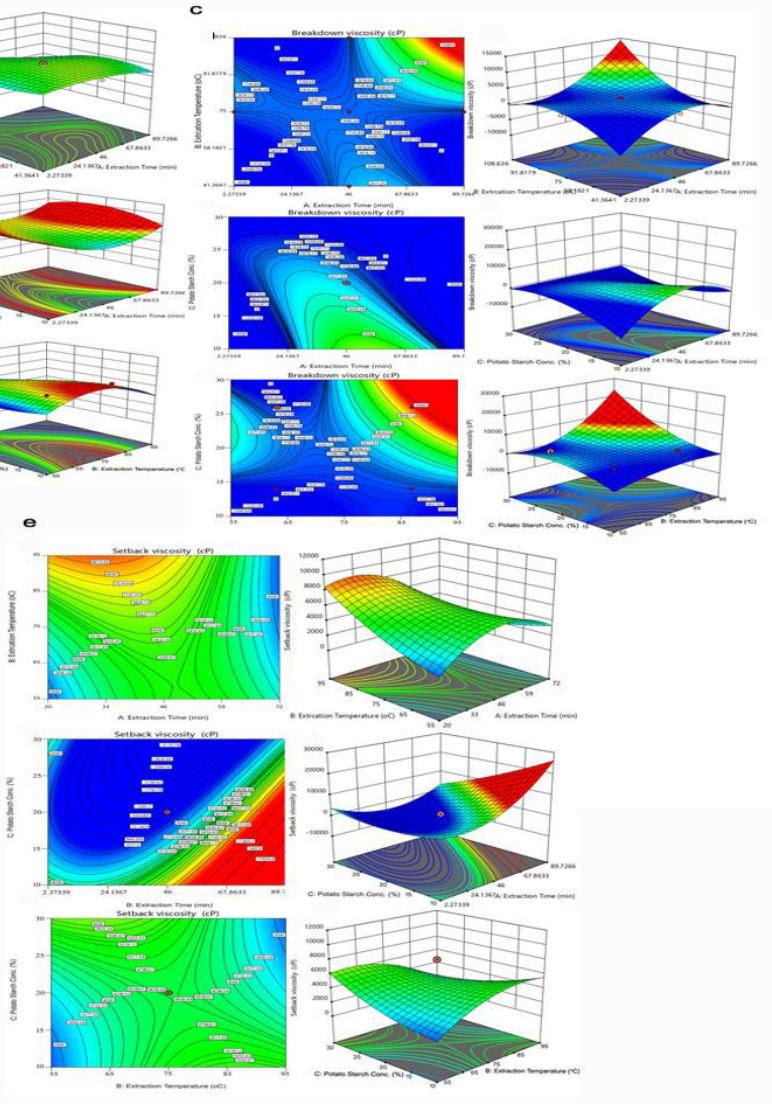

Figure 1. Response surface and contour plots for pasting parameters; PT (a), PV (b), BV (c), FV (d) and SV (e).

No. 1 and 12 were shown to be in fair agreement with those of mode-predicted values. FV showed significant variations with corresponding rises in extraction time, temperature and potato starch concentration. These findings are in line with the previously reported results of Li et al. (2014) who also concluded that amylopectin-rich starches exhibited higher PV, BV, FV and SV values. Generally, the increases in sugar and starch concentrations are positively correlated to increased gelatinization temperatures and lead to enhanced degree of retrogradation (Sun et al., 2014).

\subsection{Effects of independent variables on gel texture properties}

The results of textural properties of potato starch gels determined by texture profile analysis obtained under CCD configuration are shown in Table 3. It was evident from the 3D response surface and contour plots that independent variables, such as extraction time, extraction temperature and potato starch concentration significantly affected $(p<0.05)$ texture. It was observed from the RSM analysis that target responses regarding texture characteristics (hardness 1 , hardness 2 , springiness and chewiness) were significantly reliant on potato starch conc. followed by extraction time and temperature. $(p<0.05)$. Hardness 1 and hardness 2 values of gels obtained from all experimental runs ranged 28.58-41.23 and 26.87-42.36 units, respectively. The average recorded values for both hardness parameters was found to be quite similar (34.24) in magnitude. It was evident from the results that central point value of hardness that independent process parameters did not exhibit any significant influence and hardness showed stability invariably. Generally, the increases in hardness was observed with corresponding rises in extraction time and potato starch concentration. Response surface and contour plots for textural parameters; hardness 1, hardness 2, springiness, and chewiness are given in Figure 2.

The springiness is also denoted with another term of elasticity which is an indicative of gel's capacity to spring back well after deformation during first applied compression (Gökșen \& Ekiz, 2019). The springiness values of potato starch gel from all experimental runs of CCD configuration was found in range of 13.78 to 15.96. At lower concentrations of potato starch, the gel exhibited lower springiness values whereas increases in potato starch caused corresponding rises in gel springiness gradually. Lower springiness value indicated loss of elasticity of gel. The experimental springiness, hardness and chewiness values were shown to be in fair agreement with those of mode-predicted values. These results are in correspondence with findings of Teng et al. (2013) who reported increases in springiness values with corresponding rises in sugar and starch concentrations.

The linear, cross-product and quadratic effects of model were fund to be statistically significant

\subsection{Effects of independent variables on gelation characteristics}

Thermal stability was monitored by evaluating key thermal parameters like Onset temperature; To $\left({ }^{\circ} \mathrm{C}\right)$, peak temperature; 

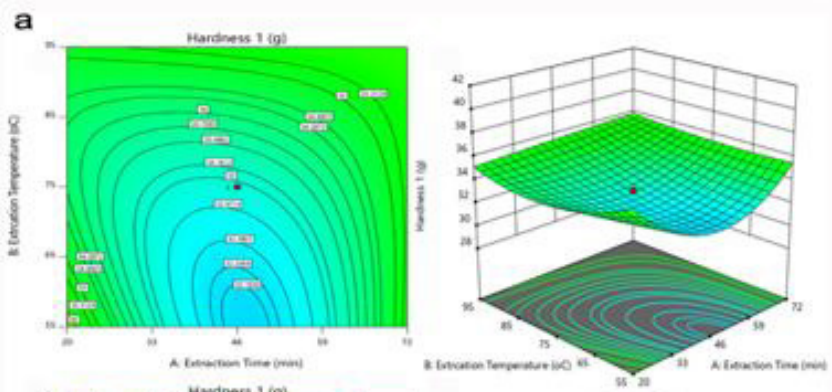

b
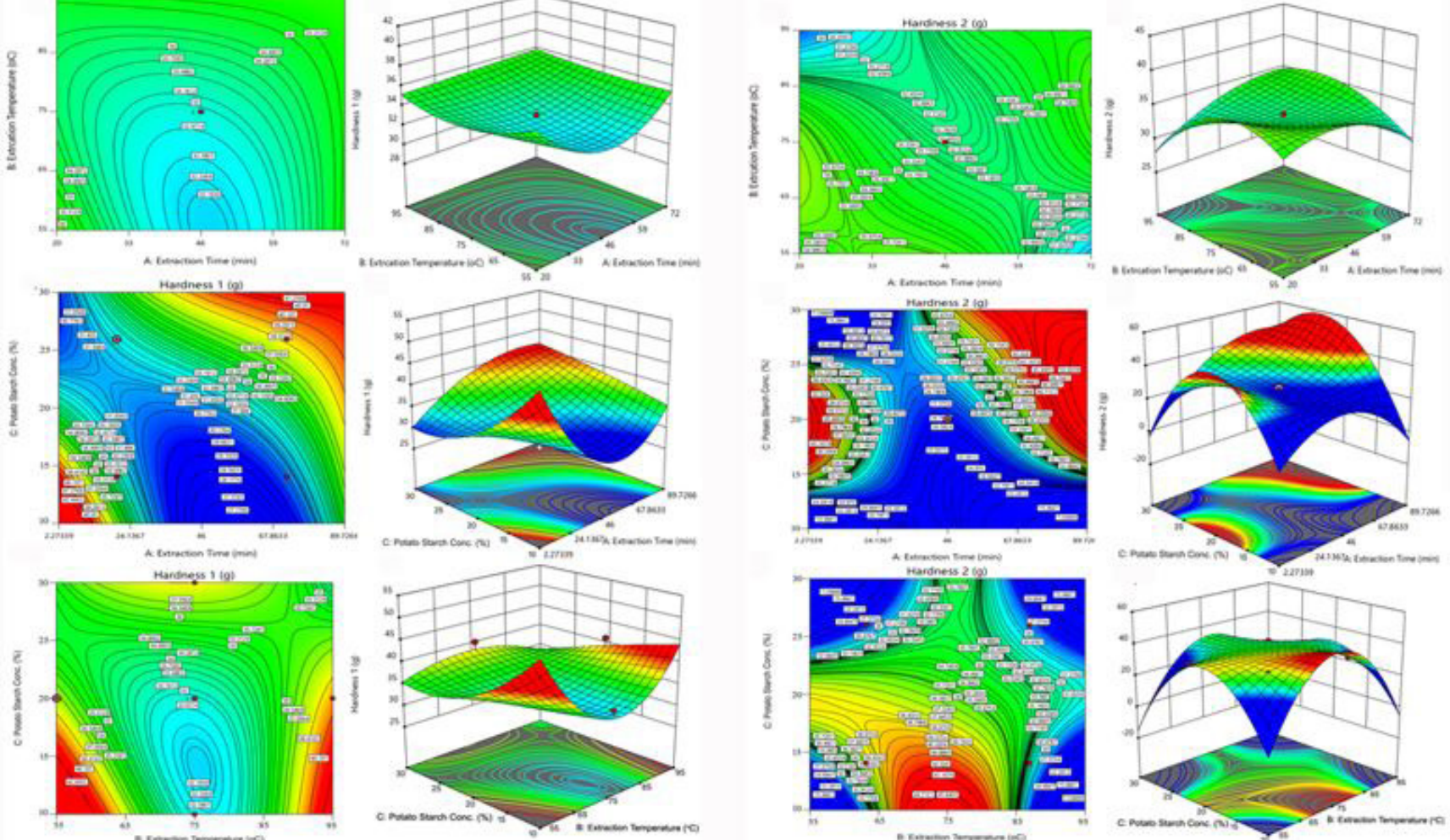

c
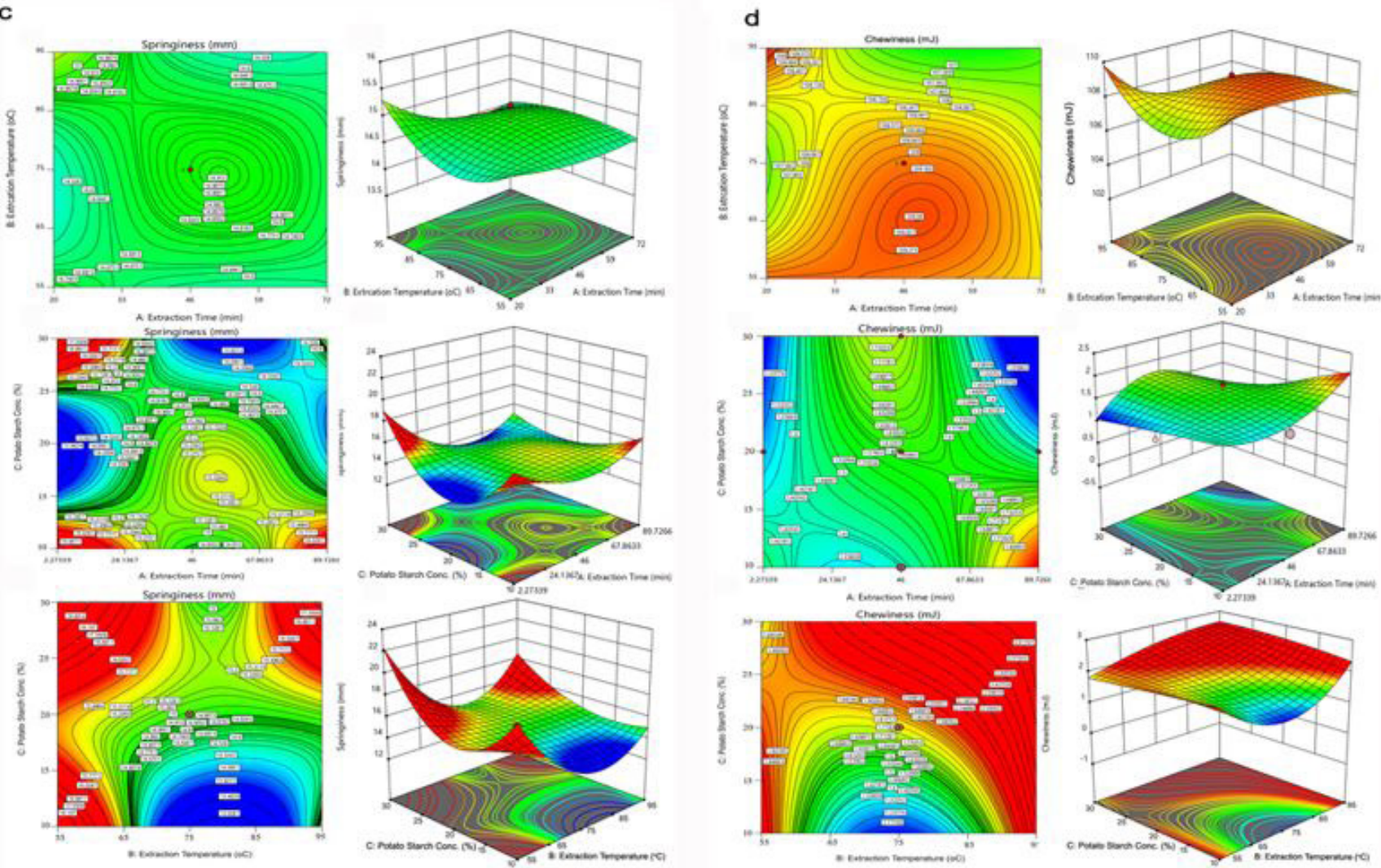

Figure 2. Response surface and contour plots for textural parameters; hardness 1 (a), hardness 2 (b), springiness (c), chewiness (d). 
a

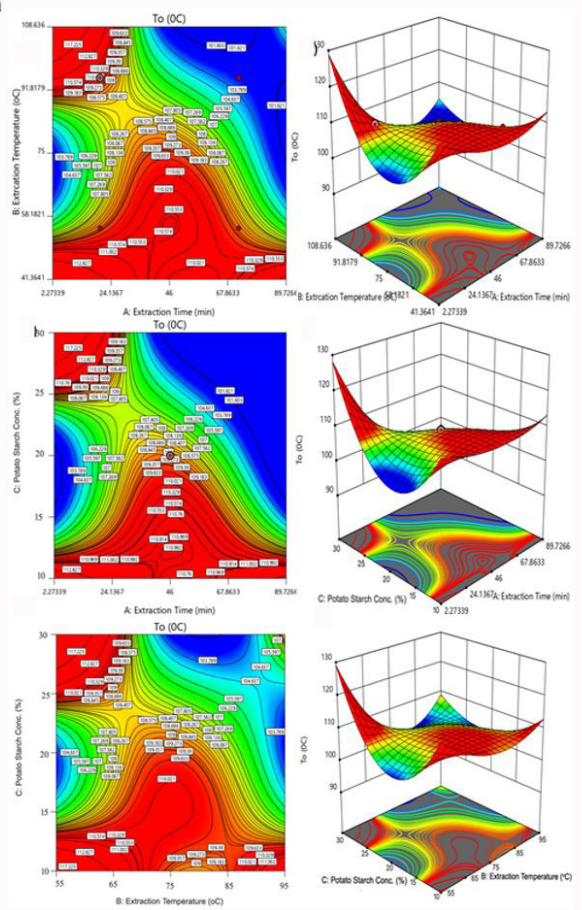

b
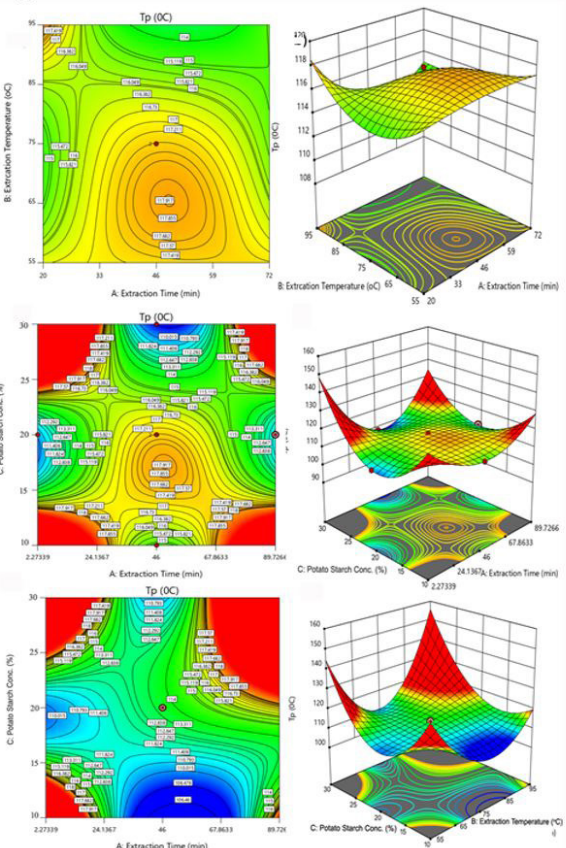
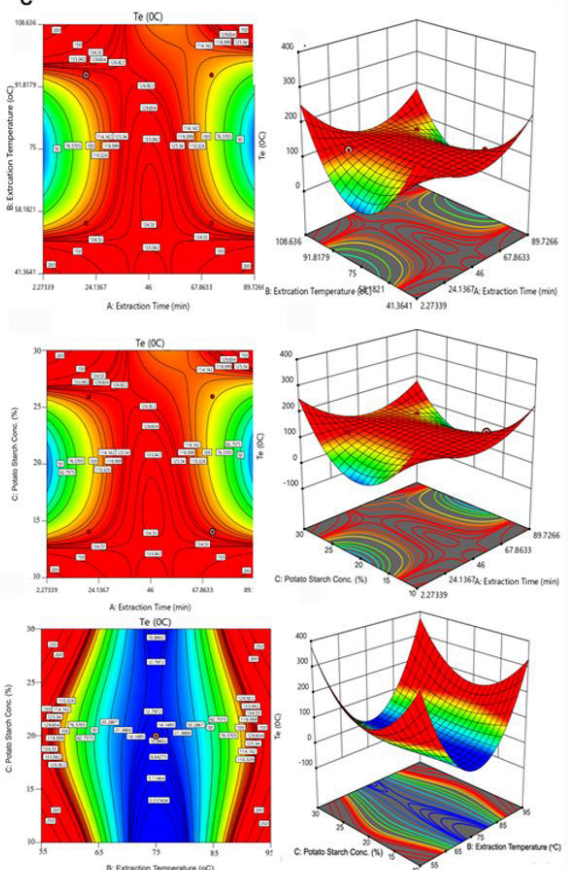

Figure 3. Response surface and contour plots for gelation parameters; $\mathrm{To}\left({ }^{\circ} \mathrm{C}\right)(\mathrm{a}), \mathrm{Tp}\left({ }^{\circ} \mathrm{C}\right)(\mathrm{b})$ and $\mathrm{Te}\left({ }^{\circ} \mathrm{C}\right)(\mathrm{c})$.

$\mathrm{Tp}\left({ }^{\circ} \mathrm{C}\right)$, and end temperature; $\mathrm{Te}\left({ }^{\circ} \mathrm{C}\right)$. The results regarding gelation characteristics of potato starch gels determined obtained under CCD configuration are shown in Table $4 . \mathrm{T}_{\mathrm{o}}$ showed range from 102.98 to $109.87^{\circ} \mathrm{C}$ whereas, the mean $\mathrm{T}_{\mathrm{o}}$ was maintained at $107.20^{\circ} \mathrm{C}$. It was evident from the results of this study that $\mathrm{T}_{\mathrm{o}}$ showed relatively consistent tendency during majority of experimental runs while a maxima $\left(109.87^{\circ} \mathrm{C}\right)$ and minima $\left(102.98^{\circ} \mathrm{C}\right)$ were observed from experimental runs No. 4 and 5 , respectively. The $\mathrm{T}_{\mathrm{o}}$ value gives the indication about degree of disintegration in internal starch granules and this disintegration led to polysaccharides release in surrounding medium. Response surface and contour plots for gelation parameters; To $\left({ }^{\circ} \mathrm{C}\right), \mathrm{Tp}$ $\left({ }^{\circ} \mathrm{C}\right)$ and $\mathrm{Te}\left({ }^{\circ} \mathrm{C}\right)$ are given in Figure 3.

Similarly, $\mathrm{T}_{\mathrm{p}}$ was ranged as $108.34-119.78^{\circ} \mathrm{C}$ whereas, the mean $\mathrm{T}_{\mathrm{p}}$ was maintained at $114.97^{\circ} \mathrm{C}$. It was evident from the results of this study that $\mathrm{T}_{\mathrm{p}}$ showed relatively slight modification during majority of experimental runs while, maxima $\left(119.78^{\circ} \mathrm{C}\right)$ and minima $\left(108.34^{\circ} \mathrm{C}\right)$ were observed from experimental runs No. 16 and 9, respectively. Generally, a high Tp is an indicative of high degree of crystallinity in starch granules (Souza et al., 2001).

$\mathrm{T}_{\mathrm{e}}$ showed range from 100.78 to $124.11^{\circ} \mathrm{C}$ whereas, the mean $\mathrm{T}_{e}$ was maintained at $114.28^{\circ} \mathrm{C}$. It was evident from the results of this study that $\mathrm{T}_{e}$ showed relatively consistent tendency during majority of experimental runs while maxima $\left(124.11^{\circ} \mathrm{C}\right)$ and minima $\left(100.78^{\circ} \mathrm{C}\right)$ were observed from experimental runs No. 17 and 1, respectively. These results in accordance with findings of Li et al. (2014).

\section{Conclusion}

The pasting temperature (PT) of gels obtained from all experimental runs ranged from 69.54 to $77.11^{\circ} \mathrm{C}$. The average recorded PT from all runs of CCD configuration was found to be $74.35{ }^{\circ} \mathrm{C}$. It was evident from the results that central point value of PT has shown most significant influence on gel formation from potato starch. The breakdown viscosity (BV) of gels obtained from all experimental runs ranged from 783 $\mathrm{cP}$ to $9210 \mathrm{cP}$. The average recorded BV from all runs of CCD configuration was found to be $1891 \mathrm{cP}$. It was evident from the results that $\mathrm{BV}$ exerted significant influence on gel formulation from potato starch. Similarly, final viscosity (FV) of gels obtained from all experimental runs ranged from $1509 \mathrm{cP}$ to $2812 \mathrm{cP}$. The average recorded FV from all runs of CCD configuration was found to be $2232 \mathrm{cP}$. FV showed significant variations with corresponding rises in extraction time and temperature.

The gels showed setback viscosity (SV) from all experimental runs in the range of $595 \mathrm{cP}$ to $9876 \mathrm{cP}$. The average recorded SV from all runs of CCD configuration was found to be $3734 \mathrm{cP}$. It was evident from the $3 \mathrm{D}$ response surface and contour plots that independent variables, such as extraction time, extraction temperature and potato starch concentration significantly affected $(p<0.05)$ texture. It was observed from the RSM analysis that target responses regarding texture characteristics (hardness 1 , hardness 2 , springiness and chewiness) were significantly reliant on potato starch conc. followed by extraction time and temperature. $\mathrm{T}_{\mathrm{o}}$ showed range from 102.98 to $109.87^{\circ} \mathrm{C}$ whereas, the mean $\mathrm{T}_{\mathrm{o}}$ was maintained at $107.20^{\circ} \mathrm{C}$. It was evident from the results of this study that $\mathrm{T}_{0}$ showed relatively consistent tendency during majority of experimental runs while a maxima $\left(109.87^{\circ} \mathrm{C}\right)$ and minima $\left(102.98^{\circ} \mathrm{C}\right)$ were observed from experimental runs No. 4 and 5 , respectively. The $\mathrm{T}_{\mathrm{o}}$ value gives the indication about degree of disintegration in internal starch granules and this disintegration led to polysaccharides release in surrounding medium. 


\section{References}

Aguilera, J. M. (1992). Generation of engineered structures in gels. In H. G. Schwartzberg \& R. W. Hartel (Eds.), Physical chemistry of foods (pp. 387-421). New York: Marcel Dekker.

Ameer, K., Chun, B. S., \& Kwon, J. H. (2017). Optimization of supercritical fluid extraction of steviol glycosides and total phenolic content from Stevia rebaudiana (Bertoni) leaves using response surface methodology and artificial neural network modeling. Industrial Crops and Products, 109, 675-682. http://dx.doi.org/10.1016/j. indcrop.2017.09.023.

Association of Official Analytical Chemists - AOAC. (2000). Official methods of analysis (17th ed.). Rockville: AOAC International

Brinckmann, J., \& Bachinger, H. P. (2005). Collagen: Primer in structure, processing a. assembly. Berlin: Springer. http://dx.doi.org/10.1007/ b98359.

De Vries, J. (2004). Hydrocolloid gelling agents and their applications. In G. O. Philips \& P. A. Williams (Eds.), Gums and stabilizers for the food industry (Vol. 12, pp. 22-30). Oxford: RSC Publ.

Freschi, J., Doran, L., Malumba, P., \& Blecker, C. (2014). Impact of freezing and thawing processes on wheat and potato starch gel syneresis. Stärke, 66(1-2), 208-215. http://dx.doi.org/10.1002/star.201200294.

Gökşen, G., \& Ekiz, H. I. (2019). Pasting and gel texture properties of starch-molasses combinations. Food Science and Technology, 39(1), 93-102. http://dx.doi.org/10.1590/fst.27817.

Imeson, A. (2000). Carrageenan. In G.O. Philips \& P. A. Williams (Eds.), Handbook of hydrocolloids (pp. 87-101). New York: Woodhead Publishing.

Jamróz, E., Juszczak, L., \& Kucharek, M. (2018). Investigation of the physical properties, antioxidant and antimicrobial activity of ternary potato starch-furcellaran-gelatin films incorporated with lavender essential oil. International Journal of Biological Macromolecules, 114, 1094-1101. PMid:29627470.

Jaswir, I., Alotaibi, A., Jamal, P., Octavianti, F., Lestari, W., Hendri, R., \& Alkahtani, H. (2016). Optimization of extraction process of plant-based gelatin replacer. International Food Research Journal, 23(6), 2519-2524.

Jobling, S. (2004). Improving starch for food and industrial applications. Current Opinion in Plant Biology, 7(2), 210-218. http://dx.doi. org/10.1016/j.pbi.2003.12.001. PMid:15003223.

Kaper, T., Van der Maarel, M. J. E. C., Euverink, G. J. W., \& Dijkhuizen, L. (2004). Exploring and exploiting starch-modifying amylomaltases from thermophiles. Biochemical Society Transactions, 32(2), 279-282. http://dx.doi.org/10.1042/bst0320279. PMid:15046589.

Kaur, A., Singh, N., Ezekiel, R., \& Guraya, H. S. (2007). Physicochemical, thermal and pasting properties of starches separated from different potato cultivars grown at different locations. Food Chemistry, 101(2), 643-651. http://dx.doi.org/10.1016/j.foodchem.2006.01.054.

Kennedy, M. J. (1979). The responses of miracidia and cercariae of Bunodera mediovitellata (Trematoda: Allocreadiidae) to light and to gravity. Canadian Journal of Zoology, 57(3), 603-609. http://dx.doi. org/10.1139/z79-071.
Li, S., Zhang, Y., Wei, Y., Zhang, W., \& Zhang, B. (2014). Thermal, pasting and gel textural properties of commercial starches from different botanical sources. Journal of Bioprocessing \& Biotechniques, 4, 4.

Liu, J., \& Xu, B. (2019). A comparative study on texture, gelatinization, retrogradation and potential food application of binary gels made from selected starches and edible gums. Food Chemistry, 296, 100-108. http://dx.doi.org/10.1016/j.foodchem.2019.05.193. PMid:31202293.

May, C. D. (2000). Pectins. In G.O. Philips \& P. A. Williams (Eds.), Handbook of hydrocolloids (pp. 169-188). New York: Woodhead Publishing.

Oakenfull, D., \& Glicksman, M. (1987). Gelling agents. CRC Critical Reviews in Food Science and Nutrition, 26(1), 1-25. http://dx.doi. org/10.1080/10408398709527460. PMid:3308320.

Phillips, G. O., \& Williams, P. A. (Eds.) (2000). Handbook of hydrocolloids (pp. 53-64). Boca Raton, FL: CRC press.

Reddy, C. K., Vidya, P. V., \& Haripriya, S. (2015). Effect of chemical modification on molecular structure and functional properties of Musa AAB starch. International Journal of Biological Macromolecules, 81, 1039-1045. http://dx.doi.org/10.1016/j.ijbiomac.2015.09.049. PMid:26432364.

Shafie, B., Cheng, S. C., Lee, H. H., \& Yiu, P. H. (2016). Characterization and classification of whole-grain rice based on rapid visco analyzer (RVA) pasting profile. International Food Research Journal, 23, 2138-2143.

Singh, N., Singh, J., Kaur, L., Sodhi, N. S., \& Gill, B. S. (2003). Morphological, thermal and rheological properties of starches from different botanical sources. Food Chemistry, 81(2), 219-231. http:// dx.doi.org/10.1016/S0308-8146(02)00416-8.

Souza, F. S., Gomes Barreto, A. P., \& Macêdo, R. O. (2001). Characterization of starch pharmaceuticals by DSC coupled to a photovisual system. Journal of Thermal Analysis and Calorimetry, 64(2), 739-743. http:// dx.doi.org/10.1023/A:1011548512655.

Sun, Q., Xing, Y., Qiu, C., \& Xiong, L. (2014). The pasting and gel textural properties of corn starch in glucose, fructose and maltose syrup. PLoS One, 9(4), 9. http://dx.doi.org/10.1371/journal.pone.0095862. PMid:24755772.

Teng, L. Y., Chin, N. L., \& Yusof, Y. A. (2013). Rheological and textural studies of fresh and freeze-thawed native sago starch-sugar gels. II. Comparisons with other starch sources and reheating effects. Food Hydrocolloids, 31(2), 156-165. http://dx.doi.org/10.1016/j. foodhyd.2012.11.002.

Tolstoguzov, V. (2002). Thermodynamic aspects of biopolymer functionality in biological systems, foods, and beverages. Critical Reviews in Biotechnology, 22(2), 89-174. http://dx.doi. org/10.1080/07388550290789478. PMid:12135168.

Torres, M. D., Chenlo, F., \& Moreira, R. (2018). Viscoelastic and textural characteristics of gels obtained from potato starch roasted under several temperature-time conditions. International Journal of Polymer Science, 2018, 7606359. http://dx.doi.org/10.1155/2018/7606359.

Zhang, C., Lim, S. T., \& Chung, H. J. (2019). Physical modification of potato starch using mild heating and freezing with minor addition of gums. Food Hydrocolloids, 94, 294-303. http://dx.doi.org/10.1016/j. foodhyd.2019.03.027. 